Revista de

Contabilidade e

Organizações
DOI: http://dx.doi.org/10.11606/rco.v8i21.60067
Journal of

Accounting and

Organizations

www.rco.usp.br

\title{
Atitude empreendedora na percepção de empreendedores individuais e sociais
}

Izabel Cristina Ferraz Barros ${ }^{\mathrm{a},}$ Lucia Rejane Da Rosa Gama Madruga $^{\mathrm{b}}$, Lucas Veiga Ávilac, Thiago Antonio Beuron ${ }^{\mathrm{d}}$

aniversidade Federal de Santa Maria

${ }^{b}$ Universidade Federal do Rio Grande do Sul

' Universidade Federal de Santa Maria

${ }^{d}$ Universidade Federal de Santa Maria

\section{Informações do Artigo}

\section{Histórico do Artigo}

Recebido: 14 de agosto de 2013

Aceito: 10 de outubro de 2014

\section{Palavras chave}

Atitude empreendedora

Empreendedor individual

Empreendedor social

\begin{abstract}
Resumo
O empreendedorismo vem se consolidando como um dos pilares para o desenvolvimento do país, por meio da geração de renda e empregos para a população. No entanto, o empreendedorismo não está centrado somente no mundo dos negócios. No contexto atual emerge uma nova vertente de empreendedorismo, conhecida como empreendedorismo social, cujo foco principal é a missão social. Inserido neste contexto, o presente estudo descritivo com abordagem quantitativa teve como propósito identificar as relações entre a atitude empreendedora de empreendedores individuais e sociais. A população foi composta por 136 gestores de empresas associados na Associação de Jovens Empreendedores Santa Maria e 36 gestores das organizações sociais cadastradas na Organização Parceiros Voluntários. Para a coleta de dados foi aplicar um questionário estruturado. Os resultados evidenciaram correlações positivas, de moderadas a altas, entre a atitude empreendedora e suas dimensões. O Teste de Mann-Whitney apontou diferença significativa entre os grupos na dimensão social. As demais dimensões apresentaram resultados estatisticamente não significativos para os dois grupos.
\end{abstract}

Copyright (C) 2014 FEA-RP/USP. Todos os direitos reservados

\section{INTRODUÇ̃̃O}

A sociedade atual está diante de grandes desafios e exigências decorrentes da própria evolução do ser humano, especialmente em função da velocidade no desenvolvimento da tecnologia de informação, da ciência, do conhecimento e da inovação. A premissa da inovação remete ao empreendedorismo como um dos pilares do desenvolvimento socioeconômico de um país, pela geração de empregos e renda para a população. Diante disso, a figura do empreendedor é determinante para enfrentar as sucessivas mudanças na economia e na sociedade (HISRICH; PETERS, 2004).

O empreendedorismo não está centrado somente no mundo dos negócios, emergindo o empreendedorismo social, que no entendimento de Melo Neto e Froes (2002), tem como foco principal a missão social, já que os empreendedores sociais buscam soluções inovadoras para os problemas sociais existentes e potenciais. Inserido neste contexto, este artigo procura

Autor Correspondente: Tel +55 3220-8379

E-mail :crisb13@hotmail.com (I. C. F. Barros); luciagm@ufsm.br (L. R. R.

G. Madruga); admlucasveiga@gmail.com (L. V. Ávila); tbeuron@gmail.

com (T. A. Beuron) articular o empreendedorismo individual com a vertente do empreendedorismo social, buscando resposta à seguinte questão de pesquisa: quais as relações que se pode estabelecer entre a atitude empreendedora de empreendedores individuais e sociais?

$\mathrm{O}$ estudo tem como principal objetivo identificar a relação entre as dimensões da atitude empreendedora a partir da percepção de empreendedores individuais e sociais. Os objetivos específicos incluem traçar o perfil dos empreendedores individuais e sociais, conhecer a atitude empreendedora dos dois grupos, analisar as relações entre atitude empreendedora dos empreendedores individuais e sociais e comparar os resultados da atitude empreendedora entre os empreendedores individuais e sociais.

O artigo está organizado em cinco seções, incluindo as notas introdutórias. A seção dois apresenta o referencial teórico; a seção três discute o método; a seção quatro os resultados; e, por fim, a quinta apresenta as considerações finais.

\section{EMPREENDORISMO INDIVIDUAL E SOCIAL: CONCEITO E COMPORTAMENTO DOS EMPREENDEDORES}

O fenômeno do empreendedorismo é relativamente 
novo, mas suas características e manifestações remontam a práticas decorrentes da antiguidade e representam o desenvolvimento econômico dos povos civilizados (DUTRA; PREVIDELLI, 2003).

A utilização do termo empreendedor teve seu início na Idade Média quando foi empregado para descrever tanto um participante quanto um administrador que gerenciava grandes projetos de produção. Nesse caso, o indivíduo não assumia grandes riscos, apenas administrava os projetos, utilizando os recursos disponíveis geralmente pelo governo do País (HISRICH; PETERS, 2004; DORNELAS, 2005). De acordo com Hisrich e Peters (2004, p.26), "a palavra entrepreneur é francesa e significa aquele que está entre ou intermediário".

Analisando-se, ainda, o contexto histórico do empreendedorismo e, conforme Filion (1999), a forma empreendedora de pequenos negócios surgiu nos anos 20 e tornou-se o principal modo de empreender na década de 1970. Esse mesmo autor salienta que a partir dos anos 80 expandiu-se em quase todos os domínios das ciências humanas e gerenciais, atraindo o interesse de especialistas de disciplinas distintas como a economia, a engenharia, as finanças, as ciências do comportamento, a gerência, o marketing entre outras e acrescenta que nos anos 90 um número cada vez maior de empreendedores optou pelo auto-emprego (FILION, 1999).

Baron e Shane (2007) definem empreendedorismo como uma área de negócios, que busca compreender de que maneira surgem as oportunidades para criar coisas novas como os produtos, os serviços, os mercados, os processos de produção e como são organizadas essas formas e as novas tecnologias, assim como são descobertas ou criadas por indivíduos que utilizam diversos meios para explorar e desenvolver algo novo e produzir grandes resultados.

Bessant e Tidd (2009) enfatizam que a prática bemsucedida da inovação e do empreendedorismo exige a interação e a integração de três diferentes perspectivas: pessoal, social e contextual, definidas como: (i) atributos pessoais ou individuais que abarcam o estilo criativo e a habilidade de identificar, avaliar e desenvolver ideias e conceitos novos; (ii) os fatores sociais ou coletivo que compreendem a contribuição de equipes, grupos e processos indispensáveis à transformação de ideias e conceitos em novos produtos, serviços ou negócios e (iii) os fatores contextuais que incluem o ambiente e os recursos necessários para tornar viável a criação e o crescimento da inovação e do empreendedorismo.

\subsection{O EMPREENDEDORISMO INDIVIDUAL}

Dornelas (2005) afirma que uma das definições mais antigas e que melhor reflete o espírito empreendedor é a de Schumpeter (1949) para quem o empreendedor é aquele que destrói a ordem econômica existente pela introdução de novos produtos e serviços, pela criação de novas formas de organização ou pela exploração de novos recursos e materiais.

Na visão de Drucker (1987, p.36), o empreendedor vê a mudança como uma norma sadia, e o define como "aquele que sempre está buscando a mudança, reage a ela e a explora como sendo uma oportunidade". Para ele o empreendedor é alguém que trabalha sozinho e exclusivamente para si. Nesta mesma linha de pensamento, Filion (1999, p.19), define “o empreendedor como uma pessoa criativa, marcada pela capacidade de estabelecer e atingir objetivos e que mantém alto nível de consciência do ambiente em que vive, usando-a para detectar oportunidades de negócios".

Schumpeter (1985, p.48) afirma que produzir coisas novas ou as mesmas com métodos diferentes, significa combinar de maneira distinta esses materiais e forças, havendo com isso uma mudança e um possível crescimento. Segundo Dornelas (2005, p.39) o empreendedor é "aquele que detecta uma oportunidade e cria um negócio para capitalizar sobre ela, assumindo riscos calculados". Esse mesmo autor destaca alguns aspectos que estão presentes em qualquer definição de empreendedorismo: (i) iniciativa para criar um novo negócio e paixão pela que faz; (ii) utilização dos recursos disponíveis de forma criativa, transformando o ambiente social e econômico onde vive; e (iii) capacidade para assumir riscos e a possibilidade de fracassar.

Alguns fatores levam os empreendedores a criar seu próprio negócio e esse crescente interesse pela atividade empreendedora de acordo com Hisrich e Peters (2004) decorre dos seguintes elementos: (i) reconhecimento da importância do empreendedorismo para a geração de empregos e para a inovação; (ii) maior divulgação por parte da mídia; e (iii) crença de que as grandes estruturas organizacionais não oferecem condições para a realização do indivíduo.

O conceito de empreendedorismo individual está ancorado na capacidade que alguns indivíduos demonstram de criar seus próprios negócios, correndo todos os riscos inerentes ao processo de criação, capitalizando os resultados para si e aproveitando da melhor forma as oportunidades que se apresentam.

\subsection{O EMPREENDEDORISMO SOCIAL}

Nos últimos anos surge um novo paradigma, caracterizado como empreendedorismo social, para o qual o objetivo não é mais o negócio das empresas, mas o negócio do social, que tem na sociedade civil o seu principal foco de atuação e na parceria envolvendo comunidade, governo e setor privado a sua estratégiabase (MELO NETO; FROES, 2002).

O empreendedorismo social surgiu em decorrência de falhas governamentais e filantrópicas e devido à ineficiência das organizações sociais em solucionar os problemas sociais, o que determinou que os empreendedores sociais fossem necessários para desenvolver novos modelos organizacionais para um novo século (DEES, 2001). Para Oliveira (2004, p.10), "o empreendedorismo social é novo em sua atual configuração, mas na sua essência já existe há muito tempo". Esse mesmo autor destaca personalidades como Luther King e Gandhi, entre outros, como empreendedores sociais, em decorrência de sua elevada capacidade de liderança e de inovação para promover mudanças sociais em larga escala.

O empreendedorismo social proporciona não só novas maneiras de abordar os problemas sociais persistentes, mas uma forma nova de pensar sobre eles, de modo que evoluiu a partir da necessidade de integrar a área econômica e a social em benefício do bem-estar da sociedade e se possível, desenvolver ações 
empreendedoras na solução dos problemas sociais vigentes dando suporte cívico, político, ético-moral e cultural (MELO NETO; FROES, 2002). Entre os desafios do empreendedorismo social Bessant e Tidd (2009), elencam alguns que precisam ser gerenciados: busca de oportunidades; seleção estratégica; implementação; estratégia de inovação; organização inovadora e vínculos poderosos.

Outra contribuição relevante a esse tema se deve a Dees (2001), ao salientar que os empreendedores sociais são uma espécie do gênero de empreendedores que têm uma missão social e atuam como agentes de mudanças sem visar à riqueza pessoal. Essa missão social é central e explícita, e isto, afeta a forma como os empreendedores sociais detectam e avaliam as oportunidades. Na avaliação de Barendsen e Gardner (2004) os empreendedores sociais são indivíduos que se aproximam de um problema social com espírito empreendedor e visão de negócio. Para eles a grande diferença entre empreendedores convencionais e sociais reside no fato de que os primeiros criam negócios e os empreendedores sociais criam mudanças.

De acordo a associação Ashoka (2011), os empreendedores sociais são indivíduos com capacidade de criar soluções inovadoras almejadas pela sociedade para os mais prementes problemas sociais. Tem como características a ambição, a persistência, são capazes de abordar grandes questões sociais e tem capacidade de oferecer novas ideias para a mudança em larga escala (ASHOKA, 2011). Nessa linha de pensamento, os autores Bessant e Tidd (2009, p.351), salientam que "empreendedores sociais percebem um problema social e utilizam os princípios empreendedores tradicionais para organizar, criar e administrar um empreendimento para realizar a mudança social".

De acordo com Thompson (2002) os empreendedores sociais podem ser encontrados em três setores: (i) negócios com fins lucrativos que tenham algum compromisso em fazer o bem ajudando a sociedade e o meio ambiente com suas estratégias e doações financeiras; (ii) nas empresas sociais, criadas com um propósito na maior parte social, mas que ainda são empresas e (iii) no setor do voluntariado ou organizações não governamentais (ONGs).

É importante observar que a busca pela inovação é uma característica que acompanha o empreendedor seja qual for a vertente conceitual que está sendo seguida. Tanto os empreendedores individuais quanto os empreendedores sociais atuam na sociedade promovendo mudanças, desconstruindo e reconstruindo os diversos espaços sociais onde atuam. Isto acontece quando um novo produto é lançado, quando um processo é redesenhado e também quando uma prática social ganha uma nova dimensão.

\subsection{AS CARACTERÍSTICAS E COMPORTAMENTO DO EMPREENDEDOR}

Na literatura, muitas são as discussões com o objetivo de obter uma melhor compreensão com relação às características presentes nos empreendedores de sucesso. Dolabela (2008) salienta que o grande questionamento dos pesquisadores é: "quais são as características dos empreendedores de sucesso"? Eles "têm algo diferente dos outros"?

Dornelas (2005) relaciona algumas características dos empreendedores que ao se somarem às características sociológicas e ambientais permitem o nascimento de uma nova empresa. Tais características demonstram que os empreendedores: são visionários; sabem tomar decisões; são indivíduos que fazem a diferença; sabem explorar ao máximo as oportunidades; são determinados e dinâmicos; são dedicados; são otimistas e apaixonados pelo que fazem; são independentes e donos do próprio destino; ficam ricos; são bem relacionados; são organizados; são planejadores; possuem conhecimentos; assumem riscos calculados; e criam valor para a sociedade.

Entre as características apontadas por Dornelas (2005), observa-se que os empreendedores são visionários e essa visão, de acordo com Filion (1993), quando projetada sobre o futuro dos negócios, é o principal fator de sucesso dos empreendedores. Ele, acrescenta que o empreendedor é alguém que imagina, desenvolve e realiza suas visões e no seu entendimento as visões classificam-se em três categorias: (i) visões emergentes; (ii) visão central e (iii) visões complementares.

Algumas características empreendedoras são inatas, outras são desenvolvidas ao longo do tempo. Mintzberg (2000) destaca que entre as diversas características atribuídas à personalidade do empreendedor está uma forte necessidade de controle, de independência e de realização, ainda ressentimento em relação à autoridade e a tendência a aceitar riscos moderados. Nos estudos desenvolvidos por McClelland (1972) e na sua Teoria Geral da Necessidade de Realização, são especificados três atributos como sendo característicos dos empreendedores: (i) responsabilidade individual para resolver problemas, estabelecer metas e atingi-las por meio de seu próprio esforço; (ii) aceitação de riscos moderados como uma função da habilidade, e não do acaso; e (iii) conhecimento dos resultados da realização da decisão/tarefa.

Para Dolabela (2008) ser empreendedor não é somente acumular conhecimentos, mas possuir atitudes, comportamentos, formas de percepção do mundo e de si mesmo, é voltar-se para atividades em que o risco e a capacidade de inovar, de ser perseverante e de conviver com a incerteza, são elementos indispensáveis. Nessa perspectiva, algumas habilidades são essenciais aos empreendedores, pois auxiliam a modelar o seu perfil. Tais habilidades são classificadas por Dornelas (2005) em três áreas distintas: (i) habilidades técnicas; (ii) habilidades gerenciais e (iii) habilidades pessoais.

Com base na crença de que o estudo da motivação contribui significativamente para o entendimento do empreendedor McClelland (1961) defende que as pessoas são motivadas por três necessidades: a) necessidade de realização; b) necessidade de poder e c) necessidade de afiliação. Para McClelland (1972) uma sociedade com um nível elevado de realização, produzirá um número maior de empreendedores ativos que darão origem a um desenvolvimento econômico mais rápido.

Nessa linha de pensamento, Filion (1999) entende que a necessidade de realização será expressa de acordo com os valores predominantes em uma sociedade e, complementa, que a necessidade de realização deve ser canalizada para o empreendedorismo e para a criação de novos empreendimentos e os valores sociais circundantes necessitam reconhecer e valorizar o sucesso nos negócios para atrair pessoas com alta necessidade de realização. Corroborando com esta visão Bernardi (2011) destaca a necessidade de realização entre as motivações e razões objetivas e subjetivas para empreender e aponta outras 
razões como a implementação de ideias, a independência, a fuga da rotina profissional, e assumir maiores responsabilidades e riscos, a prova de capacidade, a auto-realização, o maior ganho, o status e o controle da qualidade de vida.

No contexto do empreendedorismo social, Bessant e Tidd (2009) enfatizam que os empreendedores sociais centralizam seus esforços em uma direção diferente, porém, socialmente valiosa e mencionam as características presentes nos empreendedores sociais: ambiciosos; motivados por uma missão; estratégicos; talentosos; e voltados para resultados. Empreendedores sociais são motivados pelo desejo de ver as coisas mudarem e produzirem retorno mensurável. A essência dos resultados é de "fazer do mundo um lugar melhor".

Goss (2005) sugere uma base social para a geração e reprodução da conduta empreendedora envolvendo a intersubjetividade própria dessa atividade, decorrente da necessidade do indivíduo empreendedor estar com outras pessoas. Para ele, a "suscetibilidade mútua" torna os indivíduos interdependentes e não-independentes, e isso proporciona a base para a ação coletiva.

O comportamento do empreendedor foi medido pela atitude empreendedora tomando-se como referência o modelo proposto por Lopez Junior e Souza (2005), denominado Instrumento de Mensuração da Atitude Empreendedora (IMAE), conforme a descrição apresentada no método.

\section{MÉTODO}

Esta pesquisa classifica-se como descritiva com uma abordagem predominantemente quantitativa (HAIR et al., 2005). A pesquisa foi aplicada a dois grupos de empreendedores denominados de empreendedores individuais e empreendedores sociais, conforme o conceito apresentado no referencial teórico. Os empreendedores individuais foram os gestores de empresas associados na Associação de Jovens Empreendedores Santa Maria (AJESM) e os empreendedores sociais, os gestores das organizações sociais cadastradas junto à Organização Parceiros Voluntários de Santa Maria.

$\mathrm{O}$ estudo considerou o universo populacional e a resposta aos questionários, no grupo dos empreendedores individuais, totalizou 136 sujeitos e no dos empreendedores sociais 36 . O universo dos empreendedores individuais era de 165 indivíduos e dos empreendedores sociais de 38 .

O instrumento de coleta de dados foi um questionário estruturado organizado em dois blocos, a saber: (i) Bloco I: Dados de Identificação e (ii) Bloco II: Atitude Empreendedora. O Bloco I estava composto por oito indicadores, a saber: sexo, faixa etária, estado civil, escolaridade, renda, tempo de exercício na profissão, tempo de atuação na organização e um indicador que interrogava o que levou o respondente a ser um empreendedor. O Bloco II foi elaborado a partir do modelo proposto por Lopez Junior e Souza (2005), denominado Instrumento de Mensuração da Atitude Empreendedora (IMAE) e apresentava inicialmente um indicador que procurou medir a atitudes empreendedora, seguida dos indicadores relacionados à percepção dos respondentes quanto às atitudes empreendedoras. composto por 36 indicadores distribuídos em quatro dimensões: (i) realização; (ii) planejamento; (iii) poder e (iv) inovação. Ancorado no referencial teórico, que ressaltou as características dos empreendedores relacionadas à sociabilidade e comunicação, intuição, suscetibilidade e interdependência, missão social, motivação, perseverança e liderança, apontadas por autores como Goss (2005), Dess (2001), Bessant e Tidd (2009), Mello Neto e Froes (2002) e Baron e Shane (2007), sugeriu-se a inclusão da dimensão social, na escala. Desse modo, o instrumento passou a contar com 46 questões, distribuídas da seguinte forma: (i) realização (Busca de oportunidades e iniciativa, persistência, aceitação de risco e comprometimento), com 9 indicadores; (ii) planejamento (estabelecimento de metas, busca de informações e planejamento e monitoramento), com 13; (iii) poder (estabelecimento de redes de contato, persuasão, liderança, independência e autoconfiança), com 8; (iv) inovação (inovação e criatividade), com 6; e (v) social (motivação, persuasão, sociabilidade, suscetibilidade mútua, interdependência e missão social), com 10.

Neste estudo optou-se pela adaptação da Escala IMAE, associando as respostas a uma escala do tipo Likert de cinco pontos, de acordo com os seguintes parâmetros: Nunca (1); Raramente (2); Algumas Vezes (3); Frequentemente (4); e Sempre (5). Tal procedimento está ancorado no entendimento de Mattar (2001) de que uma escala com mais de sete categorias causa dificuldade para os pesquisadores sem melhor exatidão da medida.

A análise dos resultados foi realizada inicialmente por meio de estatísticas descritivas, baseadas nas frequências das respostas, com o objetivo de traçar o perfil e discutir os traços mais marcantes da atitude empreendedora dos pesquisados. Posteriormente, analisou-se a consistência interna por meio do Alfa de Cronbach. A seguir foi aplicada a técnica de Análise Fatorial Exploratória, com o intuito de analisar e eliminar indicadores cuja comunalidade fosse inferior a 0,4 , sendo excluídos 6 indicadores relativos às dimensões realização, inovação e social.

Após a análise fatorial, com a finalidade de estabelecer a relação entre as dimensões da atitude empreendedora, utilizou-se o Coeficiente de Correlação de Pearson que indica a força de associação entre duas variáveis (HAIR et al.,2005). O teste de Shapiro-Wilk testou a normalidade dos dados. Por fim, utilizou-se o Teste de Mann-Whitney que para Malhotra (2006) serve para comparar os postos entre dois grupos distintos e verificar a existência de diferenças significativas entre os grupos.

\section{AS EVIDÊNCIAS EMPÍRICAS DA PESQUISA}

Os resultados evidenciam, dentre outros aspectos, que no grupo dos empreendedores individuais há um predomínio do sexo masculino e, no dos empreendedores sociais, do sexo feminino.

É possível perceber que a escolaridade nos dois grupos é elevada e que o grupo dos empreendedores sociais é mais maduro do que o grupo dos empreendedores individuais. Além disso, a renda no grupo dos empreendedores individuais é mais elevada do que no grupo dos empreendedores sociais (Tabela 1). 
Tabela 1. Caracterização do perfil dos pesquisados

\begin{tabular}{|c|c|c|}
\hline INDICADORES & Empreendedor Individual & Empreendedor Social \\
\hline Sexo & $71,32 \%$ masculino & $66,67 \%$ feminino \\
\hline Faixa etária & $55,88 \%$ com menos de 40 anos & $55,55 \%$ com mais de 40 anos \\
\hline Estado civil & 50,74 casados & 58,33 casados \\
\hline Grau de escolaridade & $63,97 \%$ com nível superior & $66,67 \%$ com nível superior \\
\hline Renda mensal & $\begin{array}{l}83,82 \% \text { com } 4 \text { ou mais salários } \\
\text { mínimos }\end{array}$ & $50 \%$ com 4 ou mais salários mínimos \\
\hline Tempo de exercício na profissão & $59,56 \%$ com mais de 11 anos & $66,67 \%$ com mais de 11 anos \\
\hline Tempo de atuação na organização & $80,15 \%$ com mais de 5 anos & $72.23 \%$ com mais de 5 anos \\
\hline Motivação para a atividade empreendedora & $31,62 \%$ influência familiar & $\begin{array}{l}25 \% \text { convivência com outro } \\
\text { empreendedor e necessidade ajudar } \\
\text { comunidade/pessoas necessitadas }\end{array}$ \\
\hline
\end{tabular}

Os resultados demonstraram que para os empreendedores individuais a influência familiar foi o principal motivo na escolha dessa atividade. Por outro lado, verifica-se uma situação inversa entre os empreendedores sociais, onde o maior percentual foi para a necessidade de ajudar a comunidade ou pessoas necessitadas e a convivência com outro empreendedor.

\subsection{A ATITUDE EMPREENDEDORA NA PERCEPÇÃO DE EMPREENDEDORES INDIVIDUAIS E SOCIAIS}

Ao apresentar os resultados relativos aos indicadores específicos, é preciso salientar que a análise pautou-se pelo maior percentual. Em todos os indicadores houve uma concentração de respostas na parte superior da escala. Diante disso, a análise priorizou o grau sempre e em um segundo momento o grau frequentemente.

Percebeu-se um equilíbrio entre os dois grupos de respondentes com relação a assertiva relacionada com a frequência com que tomam atitudes empreendedoras, uma vez que $51,47 \%$ do grupo individual e $47,22 \%$ do grupo social, declarou tomar atitudes empreendedoras frequentemente, enquanto que para a opção sempre esse percentual foi de $24,26 \%$ para os empreendedores individuais e $25,00 \%$ para os empreendedores sociais. Tabela 2. Síntese da dimensão realização
$\mathrm{Na}$ dimensão realização, verifica-se uma distribuição equilibrada de indicadores com resposta nos graus sempre e frequentemente da escala na Tabela 2. O indicador, Responsabilizo-me pela conclusão dos trabalhos nos prazos estipulados, foi o que apresentou o resultado mais expressivo para os dois grupos analisados, concentrando o maior percentual no grau sempre da escala. Chama a atenção o fato de que o percentual para o grupo dos empreendedores sociais é maior do que para o grupo dos empreendedores individuais.

Para os empreendedores sociais os indicadores, Junto-me aos colaboradores nas tarefas para cumprir os prazos e Faço sacrificios pessoais para concluir tarefas apresentaram o segundo resultado mais expressivo (58,33\%), seguido do indicador Emprego esforços extras para a conclusão de tarefas programadas $(55,56 \%)$. O segundo resultado mais expressivo para os empreendedores individuais foi no indicador Faço sacrificios pessoais para concluir tarefas $(48,53 \%)$ e o terceiro foi no indicador Emprego esforços extras para a conclusão de tarefas programadas $(42,65 \%)$. O terceiro resultado mais expressivo novamente coincide entre os dois grupos, porém vale destacar que assim como nos demais, o resultado para o grupo dos empreendedores sociais é sempre mais expressivo do que nos empreendedores individuais, ou seja, os percentuais são mais elevados. Todos esses indicadores tiveram maior concentração de respostas no grau sempre da escala.

\begin{tabular}{|c|c|c|c|c|c|c|}
\hline Indicadores & Empreendedor & $\mathbf{N}$ & $\mathbf{R}$ & AV & $\mathbf{F}$ & $\mathbf{S}$ \\
\hline \multirow{2}{*}{$\begin{array}{l}\text { Exploro novas oportunidades de negócio/ } \\
\text { organização/ projeto. }\end{array}$} & Individual & & 6,62 & 30,15 & 41,18 & 22,06 \\
\hline & Social & & 5,56 & 33,33 & 47,22 & 13,89 \\
\hline \multirow{2}{*}{$\begin{array}{l}\text { Responsabilizo-me pela conclusão dos trabalhos } \\
\text { nos prazos estipulados. }\end{array}$} & Individual & & & 5,88 & 38,24 & 55,88 \\
\hline & Social & & & 11,11 & 22,22 & 66,67 \\
\hline \multirow{2}{*}{$\begin{array}{l}\text { Junto-me aos colaboradores nas tarefas para } \\
\text { cumprir os prazos. }\end{array}$} & Individual & & 3,68 & 12,50 & 43,38 & 40,44 \\
\hline & Social & & & 5,56 & 36,11 & 58,33 \\
\hline \multirow{2}{*}{ Faço sacrifícios pessoais para concluir tarefas. } & Individual & & 1,47 & 15,44 & 34,56 & 48,53 \\
\hline & Social & & & 11,11 & 30,56 & 58,33 \\
\hline \multirow{2}{*}{$\begin{array}{l}\text { Mantenho meus objetivos mesmo diante de } \\
\text { resultados que não são satisfatórios inicialmente. }\end{array}$} & Individual & & 3,68 & 19,12 & 47,79 & 29,41 \\
\hline & Social & & & 22,22 & 38,89 & 38,89 \\
\hline \multirow{2}{*}{ Renovo meus esforços para superar obstáculos. } & Individual & & 0,74 & 11,76 & 46,32 & 41,18 \\
\hline & Social & & & 19,44 & 41,67 & 38,89 \\
\hline \multirow{2}{*}{$\begin{array}{l}\text { Emprego esforços extras para a conclusão de } \\
\text { tarefas programadas. }\end{array}$} & Individual & 0,74 & 0,74 & 13,24 & 42,65 & 42,65 \\
\hline & Social & & & 16,67 & 27,78 & 55,56 \\
\hline \multirow{2}{*}{$\begin{array}{l}\text { Assumo riscos com o intuito de superar a } \\
\text { concorrência. }\end{array}$} & Individual & 1,47 & 7,35 & 26,47 & 41,95 & 22,79 \\
\hline & Social & 11,11 & 19,44 & 36,11 & 27,78 & 5,56 \\
\hline \multirow{2}{*}{$\begin{array}{l}\text { Assumo riscos para expandir meu negócio/ } \\
\text { organiz/projeto. }\end{array}$} & Individual & & 5,15 & 23,53 & 46,32 & 25,00 \\
\hline & Social & 2,78 & 11,11 & 33,33 & 38,89 & 13,89 \\
\hline
\end{tabular}


Com maior concentração no grau frequentemente da escala ficou evidenciado que os indicadores, Mantenho meus objetivos mesmo diante de resultados que não são satisfatórios inicialmente, Renovo meus esforços para superar resultados, Assumo riscos com o intuito de superar a concorrência e Assumo riscos para expandir meu negócio/organiz./projeto, apresentaram melhores resultados para o grupo dos empreendedores individuais com percentuais de $47,79 \% ; 46,32 \% ; 41,95 \%$ e $46,32 \%$, respectivamente. Somente o indicador Exploro novas oportunidades de negócio/organização/projeto, obteve melhor desempenho no grupo dos empreendedores sociais $(47,22 \%)$.

Em síntese, percebe-se que naqueles indicadores em que o foco está na responsabilização, no esforço e na persistência, os empreendedores sociais apresentaram percentuais mais expressivos, concentrando-se no grau sempre da escala, já nos indicadores relativos à aceitação do risco, os empreendedores individuais tiveram melhor desempenho, apesar de se posicionarem com maior frequência no grau frequentemente.
$\mathrm{Na}$ dimensão planejamento nota-se que os dois grupos de respondentes tiveram um posicionamento semelhante, ao definirem na maioria dos itens questionados que frequentemente adotam os procedimentos que compõe a dimensão (Tabela 3). Os indicadores que tiveram maior percentual de resposta no grau sempre da escala foram Busco informações sobre o meu ramo de atividades em diferentes fontes e Calculo os riscos antes de novos investimentos para o grupo dos empreendedores individuais. Também para o grupo dos empreendedores individuais Consulto meus registros de controle antes de tomar decisões, com 37,50\%. Nesses indicadores os empreendedores sociais indicaram que adotam frequentemente este comportamento com percentuais de $52,78 \% ; 44,44 \%$ e $61,11 \%$, respectivamente. O indicador, Mudo de estratégia se necessário, para alcançar uma meta apresentou $36,11 \%$ para o grupo dos empreendedores sociais no grau sempre da escala e $38,97 \%$ no grau frequentemente para os empreendedores individuais.

Tabela 3. Síntese da dimensão planejamento

\begin{tabular}{|c|c|c|c|c|c|c|}
\hline Indicadores & Empreendedor & $\mathbf{N}$ & $\mathbf{R}$ & $\mathbf{A V}$ & $\mathbf{F}$ & $\mathbf{S}$ \\
\hline \multirow{2}{*}{$\begin{array}{l}\text { Mudo de estratégia se necessário, para alcançar uma } \\
\text { meta. }\end{array}$} & Individual & & 4,41 & 28,68 & 38,97 & 27,94 \\
\hline & Social & & & 30,56 & 33,33 & 36,11 \\
\hline \multirow{2}{*}{ Defino metas de longo prazo, claras e específicas. } & Individual & 2,21 & 8,82 & 34,56 & 38,24 & 16,18 \\
\hline & Social & & 8,33 & 19,44 & 61,11 & 11,11 \\
\hline \multirow{2}{*}{$\begin{array}{l}\text { Adoto proc. } \mathrm{p} \text { / assegurar que o trabalho atenda } \\
\text { padrões de qualidade previamente estipulados. }\end{array}$} & Individual & & 3,68 & 19,85 & 41,18 & 35,29 \\
\hline & Social & & & 16,67 & 47,22 & 36,11 \\
\hline \multirow{2}{*}{$\begin{array}{l}\text { Busco obter informações sobre possíveis clientes/ } \\
\text { beneficiário. }\end{array}$} & Individual & & 0,74 & 23,56 & 48,53 & 32,35 \\
\hline & Social & & & 11,11 & 50,00 & 38,89 \\
\hline \multirow{2}{*}{$\begin{array}{l}\text { Faço projeções claras para o futuro do meu negócio/ } \\
\text { org./projeto }\end{array}$} & Individual & 2,21 & 4,41 & 25,00 & 47,06 & 21,32 \\
\hline & Social & & 2,78 & 22,22 & 41,67 & 33,33 \\
\hline \multirow{2}{*}{$\begin{array}{l}\text { Busco informações sobre meu ramo de atividades em } \\
\text { diferentes fontes. }\end{array}$} & Individual & 0,74 & 0,74 & 8,09 & 44,12 & 46,32 \\
\hline & Social & & & 5,56 & 52,78 & 41,67 \\
\hline \multirow{2}{*}{$\begin{array}{l}\text { Consulto meus registros de controle antes de tomar } \\
\text { decisões. }\end{array}$} & Individual & 0,74 & 6,62 & 24,26 & 30,88 & 37,50 \\
\hline & Social & 2,78 & 5,56 & 11,11 & 61,11 & 19,44 \\
\hline \multirow{2}{*}{$\begin{array}{l}\text { Planejo. as atividades do meu neg. subdividindo } \\
\text { tarefas de grande porte em subtarefas }\end{array}$} & Individual & 0,74 & 5,88 & 20,59 & 50,74 & 22,06 \\
\hline & Social & & & 19,44 & 50,00 & 30,56 \\
\hline \multirow{2}{*}{ Defino continuamente objetivos de curto prazo. } & Individual & 1,47 & 2,94 & 21,32 & 53,68 & 20,59 \\
\hline & Social & & 2,78 & 36,11 & 52,78 & 8,33 \\
\hline \multirow{2}{*}{ Ajo antes de ser pressionado pelas circunstâncias. } & Individual & & 2,94 & 33,82 & 44,85 & 18,38 \\
\hline & Social & 2,78 & 5,56 & 33,33 & 44,44 & 13,89 \\
\hline \multirow{2}{*}{$\begin{array}{l}\text { Costumo calcular o risco envolvido nos negócios/ } \\
\text { projetos que faço. }\end{array}$} & Individual & 0,74 & 8,82 & 17,65 & 38,24 & 34,56 \\
\hline & Social & & & 22,22 & 44,44 & 33,33 \\
\hline \multirow{2}{*}{ Calculo os riscos antes de novos investimentos. } & Individual & 1,47 & 3,68 & 15,44 & 35,29 & 46,12 \\
\hline & Social & 2,78 & 2,78 & 13,89 & 44,44 & 36,11 \\
\hline \multirow{2}{*}{ Reviso continuamente objetivos de curto prazo. } & Individual & 0,74 & 5,88 & 25,00 & 47,06 & 21,32 \\
\hline & Social & & & 25,00 & 55,56 & 19,44 \\
\hline
\end{tabular}

Os indicadores a seguir analisados tiveram maior concentração de respostas no grau frequentemente da escala. No indicador Defino metas de longo prazo, claras e especificas mais da metade da amostra dos empreendedores sociais $(61,11 \%)$ indicaram que frequentemente tem este hábito, contra $38,24 \%$ dos empreendedores individuais.

Destaca-se que os indicadores Planejo as atividades do meu negócio subdividindo tarefas de grande porte em subtarefas; Defino continuamente objetivos de curto prazo, e Ajo antes de ser pressionado pelas circunstâncias, apresentaram percentuais muito semelhantes para os dois grupos, girando em torno de $50 \%$. Chama a atenção o indicador Costumo calcular o risco envolvido nos negócios/organização/projetos que faço, cujo desempenho é melhor para o grupo de empreendedores sociais do que para os individuais. Também o indicador Reviso continuamente objetivos de curto prazo, apresentou resultados mais expressivos para os empreendedores sociais do que para os individuais.

A dimensão planejamento apresentou resultados que surpreenderam, uma vez que os indicadores relativos à definição de metas, informações sobre clientes, objetivos de curto prazo, apresentaram resultados mais favoráveis 
aos empreendedores sociais do que aos empreendedores individuais. Em tese, este resultado deveria ter desempenho contrário.

$\mathrm{Na}$ dimensão poder constata-se na Tabela 4 que nos dois grupos de respondentes a maioria dos indicadores posicionou-se no grau sempre da escala. O maior índice na escolha dos dois grupos está relacionado ao indicador Assumo a responsabilidade pela resolução de problemas que possam prejudicar o desempenho do meu negócio/organização, com 61,03\% para o grupo dos

Tabela 4. Síntese da dimensão poder empreendedores individuais e 55,56\% para os sociais.

No grau sempre da escala, o indicador Estimulo o espírito de equipe entre meus funcionários obteve resultado mais expressivo no grupo dos empreendedores sociais e menos expressivo no grupo dos empreendedores individuais. $\mathrm{O}$ indicador Considero-me principal responsável pelo desempenho do meu negócio/ organização/projeto, obteve o percentual de 52,21\% para os empreendedores individuais contra $41,67 \%$ para os sociais.

\begin{tabular}{|c|c|c|c|c|c|c|}
\hline Indicadores & Empreendedor & $\mathbf{N}$ & $\mathbf{R}$ & $\mathbf{A V}$ & $\mathbf{F}$ & $\mathbf{S}$ \\
\hline \multirow{2}{*}{ Utilizo contatos pessoais para atingir meus objetivos. } & Individual & & 11,03 & 25,00 & 36,76 & 27,21 \\
\hline & Social & & 2,78 & 16,67 & 33,33 & 47,22 \\
\hline \multirow{2}{*}{ Utilizo estratégias deliberadas para influenciar pessoas } & Individual & 2.21 & 13,24 & 33,82 & 37,50 & 13,24 \\
\hline & Social & 5,56 & 16,67 & 25,00 & 30,56 & 22,22 \\
\hline \multirow{2}{*}{$\begin{array}{l}\text { Assumo a responsabilidade pela resolução de problemas que } \\
\text { possam prejudicar o desempenho do meu negócio/organização/ } \\
\text { projeto. }\end{array}$} & Individual & & & 3,68 & 35,29 & 61,03 \\
\hline & Social & & & 16,67 & 27,78 & 55,56 \\
\hline \multirow{2}{*}{$\begin{array}{l}\text { Considero-me principal responsável pelo desempenho do meu } \\
\text { negócio/organização/projeto }\end{array}$} & Individual & 2,21 & 4,41 & 18,38 & 22,79 & 52,21 \\
\hline & Social & 2,78 & 8,33 & 27,78 & 19,44 & 41,67 \\
\hline \multirow{2}{*}{ Estimulo o espírito de equipe entre meus funcionários. } & Individual & & & 7,35 & 38,97 & 53,68 \\
\hline & Social & & & 5,56 & 30,56 & 63,89 \\
\hline \multirow{2}{*}{$\begin{array}{l}\text { Estimulo a participação dos funcionários na busca pela solução de } \\
\text { um problema. }\end{array}$} & Individual & & 2,21 & 4,41 & 40,44 & 52,94 \\
\hline & Social & & & 11,11 & 36,11 & 52,78 \\
\hline \multirow{2}{*}{ Confio na minha capacidade de superar desafios. } & Individual & & & 6,62 & 34,56 & 58,82 \\
\hline & Social & & & 5,56 & 36,11 & 58,33 \\
\hline \multirow{2}{*}{$\begin{array}{l}\text { Confio na minha competência como fonte do sucesso do meu } \\
\text { negócio/organização/projeto. }\end{array}$} & Individual & & 0,74 & 7,35 & 38,97 & 52,94 \\
\hline & Social & & & 27,78 & 33,33 & 38,89 \\
\hline
\end{tabular}

Destaca-se que o indicadores, Estimulo a participação dos funcionários na busca pela solução de um problema e Confio na minha capacidade de superar desafios apresentaram resultados muito semelhantes com percentuais acima de $50 \%$.

$\mathrm{Na}$ dimensão poder pode-se perceber que os empreendedores individuais possuem maior independência e autoconfiança do que os empreendedores sociais. Em contrapartida, os empreendedores sociais fazem maior uso da rede de contatos e do apoio dos colaboradores.

Na dimensão inovação, nota-se que os dois grupos de respondentes tiveram um posicionamento semelhante, ao definirem na maioria dos itens questionados que frequentemente adotam os procedimentos que compõe a dimensão (Tabela 5). O indicador Implemento novas ideias com o objetivo de melhorar a qualidade do meu negócio/organização/projeto apresentou resultado mais favorável no grupo dos empreendedores sociais $(58,33 \%)$ do que nos individuais $(45,59 \%)$. O indicador de Busco novas maneiras de realizar tarefas, obteve o melhor desempenho do grupo social.

$\mathrm{O}$ indicador, Crio novas rotinas objetivando a melhoria do desempenho do meu negócio/organização/ projeto teve $52,78 \%$ para os empreendedores sociais e 49,26\% para os individuais. O indicador Busco novas soluções para atender necessidades de clientes/ usuários/ beneficiários o melhor desempenho foi para os empreendedores sociais.

Foge ao contexto dos demais o indicador Procuro criar novos serviços, que obteve $41,67 \%$ para a alternativa algumas vezes, no grupo de empreendedores sociais e de $36,76 \%$ na alternativa frequentemente para os empreendedores individuais.

Tabela 5. Síntese da dimensão Inovação

\begin{tabular}{|c|c|c|c|c|c|c|}
\hline Indicadores & Empreendedor & $\mathbf{N}$ & $\mathbf{R}$ & AV & $\mathbf{F}$ & $\mathbf{S}$ \\
\hline \multirow{2}{*}{$\begin{array}{l}\text { Implemento novas idéias com o objetivo de melhorar a } \\
\text { qualidade do meu negócio/org/projeto. }\end{array}$} & Individual & & 0,74 & 18,38 & 45,59 & 35,29 \\
\hline & Social & & 2,78 & 13,89 & 58,33 & 25,00 \\
\hline \multirow{2}{*}{ Busco novas maneiras de realizar tarefas } & Individual & & 0,74 & 26,47 & 47,79 & 25,00 \\
\hline & Social & & & 8,33 & 66,67 & 25,00 \\
\hline \multirow{2}{*}{ Procuro criar novos serviços } & Individual & 0,74 & 11,03 & 29,41 & 36,76 & 22,06 \\
\hline & Social & & 5,56 & 41,67 & 38,89 & 13,89 \\
\hline \multirow{2}{*}{ Desenvolvo idéias novas para a solução de problemas } & Individual & & 2,21 & 17,65 & 52,21 & 27,94 \\
\hline & Social & & & 22,22 & 52,78 & 25,00 \\
\hline \multirow{2}{*}{$\begin{array}{l}\text { Crio novas rotinas, objetivando a melhoria do desempenho do } \\
\text { meu negócio/organização/projeto. }\end{array}$} & Individual & & 5,88 & 23,53 & 49,26 & 21,32 \\
\hline & Social & & 8,33 & 22,22 & 52,78 & 16,67 \\
\hline \multirow{2}{*}{$\begin{array}{l}\text { Busco novas soluções para atender necessidades de clientes/ } \\
\text { usuários/ beneficiários. }\end{array}$} & Individual & & 1,47 & 5,88 & 50,74 & 41,91 \\
\hline & Social & & & 5,56 & 58,33 & 36,11 \\
\hline
\end{tabular}


É importante salientar que na dimensão inovação percebe-se que os empreendedores individuais obtiveram resultados mais expressivos somente no indicador de inovação em serviços, nos demais, relacionados à criatividade, o desempenho do empreendedor social foi mais expressivo.

Na dimensão social, predominam as respostas no grau sempre da escala (Tabela 6). Novamente os resultados são mais expressivos na maior parte dos indicadores para o grupo dos empreendedores sociais.

$\mathrm{O}$ indicador com resultados mais expressivos dentre todos os indicadores analisados em todas as dimensões foi Procuro manter uma atitude de respeito, solidariedade e ajuda mútua com as demais pessoas que atuam em meu negócio/organização/ Projeto, com resultados mais favoráveis ao grupo dos empreendedores sociais $(83,33 \%)$ do que ao dos empreendedores individuais $(78,68 \%)$.

Tabela 6. Síntese da dimensão social

\begin{tabular}{|c|c|c|c|c|c|c|}
\hline Indicadores & Empreendedor & $\mathbf{N}$ & $\mathbf{R}$ & AV & $\mathbf{F}$ & $\mathbf{S}$ \\
\hline \multirow{2}{*}{$\begin{array}{l}\text { Sinto-me motivado com as atividades que desenvolvo em meu } \\
\text { negócio/organização/projeto }\end{array}$} & Individual & & 2,21 & 11,76 & 40,44 & 45,59 \\
\hline & Social & & & 5,56 & 36,11 & 58,33 \\
\hline \multirow{2}{*}{$\begin{array}{l}\text { Faço uso do carisma pessoal para negociar e atrair os outros } \\
\text { para causas próprias.. }\end{array}$} & Individual & 2,21 & 7,35 & 22,06 & 36,03 & 32,35 \\
\hline & Social & 5,56 & 5,56 & 16,67 & 36,11 & 36,11 \\
\hline \multirow{2}{*}{$\begin{array}{l}\text { Procuro manter uma atitude de respeito, solidariedade e ajuda } \\
\text { mútua com as demais pessoas que atuam em meu negócio/ } \\
\text { organização/projeto. }\end{array}$} & Individual & & & 1,47 & 19,85 & 78,68 \\
\hline & Social & & & & 16,67 & 83,33 \\
\hline \multirow{2}{*}{$\begin{array}{l}\text { Deposito confiança nas pessoas que atuam em meu negócio/ } \\
\text { organização/projeto.. }\end{array}$} & Individual & & & 8,09 & 36,76 & 55,15 \\
\hline & Social & & & 5,56 & 41,67 & 52,78 \\
\hline \multirow{2}{*}{$\begin{array}{l}\text { Busco soluções para minimizar problemas relacionados com a } \\
\text { exclusão social }\end{array}$} & Individual & 0,74 & 13,24 & 30,15 & 33,82 & 22,06 \\
\hline & Social & & & 2,78 & 25,00 & 72,22 \\
\hline \multirow{2}{*}{$\begin{array}{l}\text { Estabeleço relacionamentos e interações com as pessoas no } \\
\text { ambiente da organização. }\end{array}$} & Individual & & 0,74 & 8,09 & 41,91 & 49,26 \\
\hline & Social & & & & 30,56 & 69,44 \\
\hline \multirow{2}{*}{$\begin{array}{l}\text { Tenho disposição para promover melhorias nos } \\
\text { relacionamentos entre as pessoas. }\end{array}$} & Individual & & 0,74 & 12,50 & 44,12 & 42,65 \\
\hline & Social & & & 5,56 & 33,33 & 61,11 \\
\hline \multirow{2}{*}{$\begin{array}{l}\text { Aprecio trabalhar em outras equipes e projetos compartilhando } \\
\text { os resultados. }\end{array}$} & Individual & 0,74 & 5,15 & 20,59 & 43,38 & 30,15 \\
\hline & Social & & 5,56 & 5,56 & 44,44 & 44,44 \\
\hline \multirow{2}{*}{$\begin{array}{l}\text { Construo redes de } \\
\text { relacionamento cultivando e utilizando contatos. }\end{array}$} & Individual & 2,21 & 7,35 & 23,53 & 40,44 & 26,47 \\
\hline & Social & & & 25,00 & 44,44 & 30,56 \\
\hline \multirow{2}{*}{ Tenho preferência por realizar tarefas individualmente } & Individual & 3,68 & 25,00 & 41,91 & 19,85 & 9,56 \\
\hline & Social & 19,44 & 16,67 & 50,00 & 8,33 & 5,56 \\
\hline
\end{tabular}

Como segundo indicador mais expressivo para o grupo dos empreendedores sociais, chama a atenção o indicador, Busco soluções para minimizar problemas relacionados com a exclusão social que apresentou percentual de $72,22 \%$ no grau sempre da escala, contra apenas $33,82 \%$ no grau frequentemente para o grupo dos empreendedores individuais.

O indicador, Estabeleço relacionamentos e interações com as pessoas no ambiente da organização obteve $69,44 \%$ para os empreendedores sociais contra $49,26 \%$ entre os empreendedores individuais na alternativa sempre. Soma se a este o indicador Tenho disposição para promover melhorias nos relacionamentos entre as pessoas, com $61,11 \%$ na escolha dos empreendedores sociais na alternativa sempre, contra apenas $44,12 \%$ dos empreendedores individuais.

Na sequência, indicador Sinto-me motivado com as atividades que desenvolvo em meu negócio/organização/ projeto, foi mais expressivo para os empreendedores sociais $(58,33 \%)$ dos empreendedores sociais do que para os individuais $(45,59 \%)$.

Também é importante destacar o indicador Deposito confiança nas pessoas que atuam em meu negócio/ organização/projeto, com percentual de $55,15 \%$ para os empreendedores individuais e $52,78 \%$ para os sociais. Este foi o único indicador em que os empreendedores sociais obtiveram resultado mais expressivo do que os empreendedores sociais.

Outro dado importante está relacionado ao indicador Faço uso do carisma pessoal para negociar e atrair os outros para causas próprias, em que os empreendedores individuais e também os sociais optaram pelo grau frequentemente, porém com um percentual baixo de apenas $36,03 \%$ para o grupo individual e $36,11 \%$ para o grupo social.

Os indicadores, Aprecio trabalhar em outras equipes e projetos compartilhando os resultados e Construo redes de relacionamento cultivando e utilizando contatos concentraram-se no grau frequentemente da escala com percentuais que giram em torno de $40 \%$ para os dois grupos, sobressaindo-se novamente o grupo dos empreendedores sociais.

O indicador, Tenho preferência por realizar tarefas individualmente obteve índices muito baixos para os graus frequentemente e sempre. Para esse indicador, os dois grupos apontaram o maior percentual de escolha no grau algumas vezes.

Em síntese, percebe-se que os empreendedores 
sociais apresentaram resultados mais expressivos em praticamente todos os indicadores, destacando-se o indicador relativo à confiança como o único em que os empreendedores individuais foram mais expressivos.

\subsection{RELAÇÃO ENTRE A ATITUDE EMPREENDEDORA DOS EMPREENDEDORES INDIVIDUAIS E SOCIAIS}

As análises de correlação de Pearson evidenciaram que no grupo dos empreendedores individuais existe correlação positiva para todos os fatores analisados. A correlação entre a atitude empreendedora (AE) e cada uma de suas dimensões demonstra que todas as associações são consideradas altas, com valores entre 0,740 (planejamento) e 0,836 (inovação), conforme mostra a Tabela 7.

Verifica-se que entre as dimensões da atitude empreendedora, a maior correlação apresentada foi entre as dimensões realização e inovação $(0,658)$, considerada moderada. Cabe ressaltar, que a menor correlação foi entre as dimensões planejamento e social, com uma associação de 0,421, considerada como moderada.

Para o grupo de empreendedores sociais as correlações entre a atitude empreendedora (AE) e cada uma das suas dimensões foram consideradas altas, com valores entre 0,731 (planejamento) e 0,880 (poder), conforme mostra a Tabela 7.

Tabela 7 - Matriz de Correlação - Empreendedores Individuais e Sociais

\begin{tabular}{|c|c|c|c|c|c|}
\hline & \multicolumn{5}{|c|}{ ATITUDE EMPREENDEDORA (A.E) - Empreendedores Individuais } \\
\hline & Realização & Planejamento & Poder & Inovação & Social \\
\hline A.E & $0,808 * *$ & $0,740 * *$ & $0,829 * *$ & $0,836 * *$ & $0,762 * *$ \\
\hline Realização & 1 & $0,468 * *$ & $0,596 * *$ & $0,658 * *$ & $0,491 * *$ \\
\hline Planejamento & & 1 & $0,569 * *$ & $0,476 * *$ & $0,421 * *$ \\
\hline Poder & & & 1 & $0,567 * *$ & $0,611 * *$ \\
\hline Inovação & & & & 1 & $0,550 * *$ \\
\hline \multirow[t]{3}{*}{ Social } & & & & & 1 \\
\hline & \multicolumn{5}{|c|}{ ATITUDE EMPREENDEDORA (A.E) - Empreendedores Sociais } \\
\hline & Realização & Planejamento & Poder & Inovação & Social \\
\hline A.E & $0,864 * *$ & $0,731 * *$ & $0,880 * *$ & $0,797 * *$ & $0,780 * *$ \\
\hline Realização & 1 & $0,594 * *$ & $0,729 * *$ & $0,610 * *$ & $0,517 * *$ \\
\hline Planejamento & & 1 & $0,553 * *$ & $0,465 * *$ & $0,430 * *$ \\
\hline Poder & & & 1 & $0,543 * *$ & $0,747 * *$ \\
\hline Inovação & & & & 1 & $0,539 * *$ \\
\hline Social & & & & & 1 \\
\hline
\end{tabular}

** Correlação é significativa ao nível de 0,01

Verifica-se que entre as dimensões da atitude empreendedora, a maior correlação apresentada foi entre as dimensões poder e social $(0,747)$, considerada alta. Cabe ressaltar, que a menor correlação foi entre as dimensões planejamento e Social com uma associação de 0,430 , considerada como moderada. A figura 1 ilustra esses resultados.
Em síntese estes resultados sugerem que quanto mais for estimulada a inovação, melhores resultados serão alcançados para a atitude empreendedora dos empreendedores individuais. Da mesma forma o poder para o grupo de empreendedores sociais.

Figura 1. Correlação entre as dimensões da atitude empreendedora (AE)

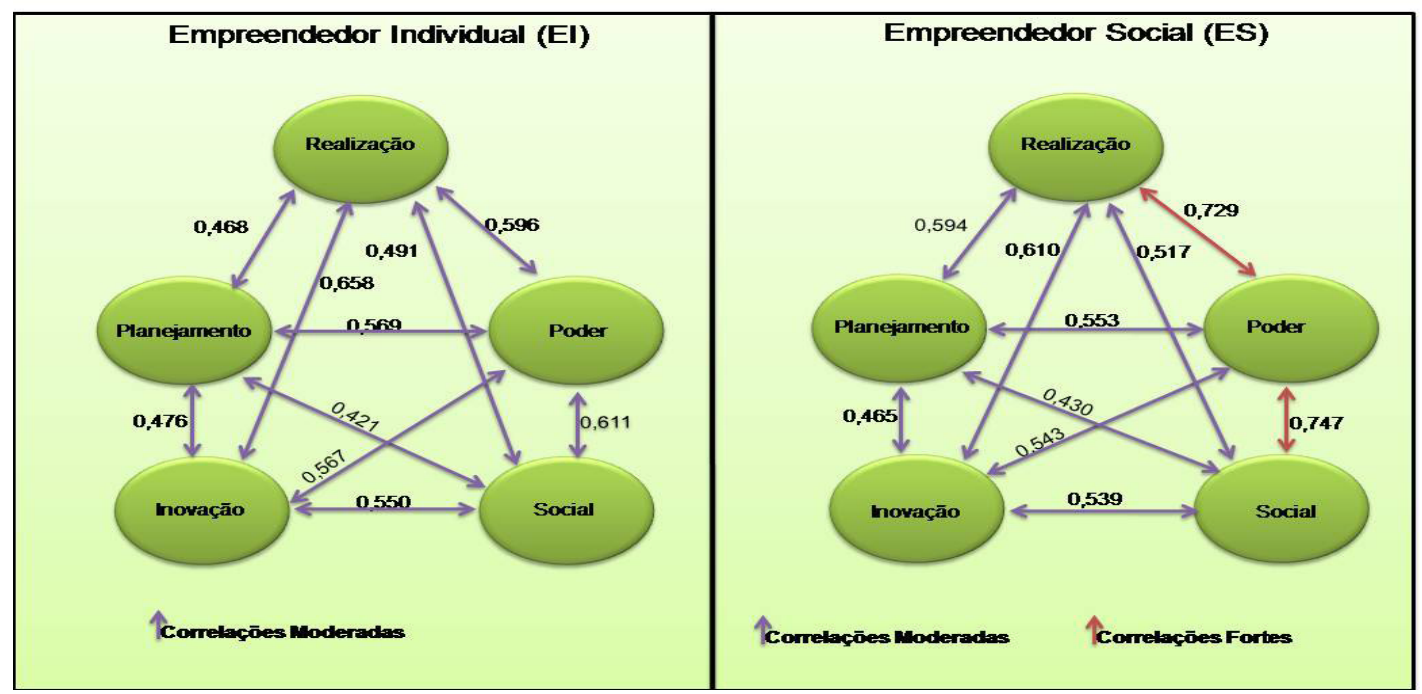


Todas as correlações foram consideradas expressivas, classificando-se como moderadas ou altas. Analisandose com mais detalhe os resultados percebe-se que para o grupo dos empreendedores individuais a realização se dá muito mais pela capacidade de inovação do que no grupo dos empreendedores sociais, no qual a realização está muito mais correlacionada com o poder.

Esse resultado corrobora a teoria que afirma que os empreendedores individuais aproveitam as oportunidades para criar negócios e capitalizar sobre eles, já os empreendedores sociais estão muito mais voltados para o estabelecimento de redes que poderão auxiliá-los na realização de mudanças sociais em larga escala.

\subsection{COMPARANDO OS RESULTADOS ENTRE OS EMPREENDEDORES INDIVIDUAIS E SOCIAIS}

Os resultados apresentados na Tabela 8 demonstram que embora, em alguns casos o teste de normalidade Shapiro-Wilk tenha apresentado resultados normais, na maioria das dimensões apresentou resultados não normais para este teste nos dois grupos pesquisados.

Tabela 8. Teste de normalidade Shapiro- Wilk

\begin{tabular}{|c|c|c|c|c|}
\hline $\begin{array}{c}\text { Atitude Empreendedora - } \\
\text { Dimensões }\end{array}$ & Grupo & Shapiro- Wilk & \multicolumn{2}{|c|}{ p-valor } \\
\hline \multirow{2}{*}{ Realização } & Individual & 0,970 & 0,0047 & Não Normal \\
\hline & Social & 0,978 & 0,6800 & Normal \\
\hline \multirow{2}{*}{ Planejamento } & Individual & 0,980 & 0,1368 & Normal \\
\hline & Social & 0,970 & 0,4300 & Normal \\
\hline \multirow{2}{*}{ Poder } & Individual & 0,958 & 0,0004 & Não Normal \\
\hline & Social & 0,935 & 0,0360 & Não Normal \\
\hline \multirow{2}{*}{ Inovação } & Individual & 0,972 & 0,0077 & Não Normal \\
\hline & Social & 0,955 & 0,1582 & Normal \\
\hline \multirow{2}{*}{ Social } & Individual & 0,966 & 0,0022 & Não Normal \\
\hline & Social & 0,938 & 0,0470 & Não Normal \\
\hline
\end{tabular}

Assim, partiu-se para o Teste não Paramétrico de Mann-Whitney com a finalidade de comparar os dois grupos. Após executar o Teste de Mann-Whitney, constatou-se que há uma diferença significativa entre o grupo de empreendedores individuais e empreendedores sociais na dimensão social, cujo nível de significância foi de $p=(0,001)$. As demais dimensões apresentaram resultados estatisticamente não significativos para os dois grupos, conforme mostra a Tabela 9. Esse resultado remete à necessidade de desenvolvimento do grupo de empreendedores individuais nos indicadores dessa dimensão, já que para esse grupo foi menos expressivo do que no grupo dos empreendedores sociais.

Tabela 9. Análise Comparativa entre os Grupos

\begin{tabular}{|c|c|c|c|c|c|}
\hline Atitude Empreendedora - Dimensões & Grupo & $\mathbf{N}$ & Média & D. Padrão & p-valor \\
\hline \multirow{2}{*}{ Realização } & Individual & 136 & 4,10 & 0,45 & \multirow{2}{*}{0,5013} \\
\hline & Social & 36 & 4,03 & 0,49 & \\
\hline \multirow{2}{*}{ Planejamento } & Individual & 136 & 3,94 & 0,48 & \multirow{2}{*}{0,5338} \\
\hline & Social & 36 & 4,00 & 0,37 & \\
\hline \multirow{2}{*}{ Poder } & Individual & 136 & 4,23 & 0,42 & \multirow{2}{*}{0,5505} \\
\hline & Social & 36 & 4,20 & 0,48 & \\
\hline \multirow{2}{*}{ Inovação } & Individual & 136 & 4,00 & 0,55 & \multirow{2}{*}{0,5577} \\
\hline & Social & 36 & 4,06 & 0,51 & \\
\hline \multirow{2}{*}{ Social } & Individual & 136 & 3,98 & 0,43 & \multirow{2}{*}{0,0001} \\
\hline & Social & 36 & 4,44 & 0,36 & \\
\hline
\end{tabular}

Retomando a análise descritiva, é possível perceber que os empreendedores individuais precisam fortalecer aspectos como a motivação, disposição para melhorar os relacionamentos e interações na organização, redes de relacionamento e especialmente a sua disposição para minimizar os problemas relacionados com a exclusão social.

\section{CONSIDERAÇÕES FINAIS}

Este estudo teve por objetivo identificar a relação entre as dimensões da atitude empreendedora na percepção dos empreendedores individuais e sociais. Observou-se que entre os empreendedores individuais há um predomínio do sexo masculino, enquanto que para os empreendedores sociais a maioria está representada pelo sexo feminino. A motivação para o exercício de atividades empreendedoras indicou que para os empreendedores individuais a influência familiar foi a alternativa que apresentou o maior percentual. Já para os empreendedores sociais foi a necessidade de ajudar as comunidades e pessoas necessitadas.

$\mathrm{Na}$ dimensão realização percebeu-se que naqueles indicadores em que o foco está na responsabilização, no esforço e na persistência, os empreendedores 
sociais apresentaram percentuais mais expressivos, já nos indicadores relativos à aceitação do risco, os empreendedores individuais tiveram melhor desempenho.

$\mathrm{Na}$ dimensão planejamento os resultados surpreenderam, uma vez que os indicadores relativos a metas, informações sobre clientes, objetivos de curto prazo tiveram resultados mais favoráveis aos empreendedores sociais. $\mathrm{Na}$ dimensão poder foi possível perceber que os empreendedores individuais possuem maior independência e autoconfiança do que os empreendedores sociais. Em contrapartida, os empreendedores sociais fazem maior uso da rede de contatos e do apoio dos colaboradores.

$\mathrm{Na}$ dimensão inovação ficou evidenciado que os empreendedores individuais obtiveram resultados mais expressivos somente no indicador de inovação em serviços, nos demais, relacionados à criatividade, 0 desempenho do empreendedor social foi mais expressivo.

$\mathrm{Na}$ dimensão social percebeu-se que os empreendedores sociais apresentaram resultados mais expressivos em praticamente todos os indicadores, destacando-se o indicador relativo à confiança como o único em que os empreendedores individuais apresentaram resultado mais expressivo.

A análise de correlação indicou alta correlação positiva entre a atitude empreendedora e cada uma de suas dimensões nos dois grupos, com destaque para a dimensão inovação no grupo de empreendedores individuais e para o poder no grupo dos empreendedores sociais.

$\mathrm{Na}$ correlação das dimensões entre si destacase moderada correlação positiva entre as dimensões realização e inovação nos empreendedores sociais e alta correlação positiva entre as dimensões realização e poder nos empreendedores sociais.

Os resultados dos testes não-paramétricos indicaram que existe diferença estatisticamente significativa entre os dois grupos analisados no que se refere à dimensão social, o que remete à necessidade de desenvolvimento do grupo de empreendedores individuais nos indicadores dessa dimensão, já que o resultado nesse grupo foi menos expressivo do que no grupo dos empreendedores sociais.

O estudo trouxe importantes contribuições à compreensão do fenômeno do empreendedorismo ao comparar dois grupos sociais importantes na transformação da sociedade e pode ser mais bem explorado com o acréscimo de novas dimensões de análise, assim como trazendo novos grupos sociais para serem comparados assim como novas temáticas relacionadas ao tema proposto, dentre as quais a competência social como uma das características dos empreendedores marcada por vários autores.

\section{REFERÊNCIAS}

ASHOKA.What is a Social Entrepreneur? Disponível em: $\quad$ http://www.ashoka.org/fellows/social entrepreneur.cfm $>$ Acesso em: 18 Jan. 2011.

BARENDSEN, L., Gardner, H. Is the social entrepreneur a new type of leader? Leader to Leader. No. 34, p. 43-50. New York: Fall, 2004.

BARON, R. A.; SHANE, S. A. Empreendedorismo: uma visão do processo. São Paulo: Thomson Learning, 2007.

BERNARDI, L. A. Manual de Empreendedorismo e Gestão: fundamentos, estratégias e dinâmicas. $1^{\mathrm{a}}$ ed. São Paulo: Atlas, 2011.

BESSANT, J.; TIDD, J. Inovação e Empreendedorismo. Porto Alegre: Bookman, 2009.

DANCEY, C. P; REIDY, J. Estatística sem matemática para psicologia. 3 ed. Porto Alegre: Artmed, 2006.

DEES, J. G. The meaning of "social entrepreneurship". 2001. Disponível em: <http://www.fuqua.duke. edu/centers/case/documents/dees SE.pdf>. Acesso em: 04 Jan.2011.

DOLABELA, F. O Segredo de Luisa. 30. ed. São Paulo: Cultura, 2006.

Oficina do Empreendedor: A metodologia do ensino que ajuda a transformar conhecimento em riqueza. Rio de Janeiro: Sextante, 2008 .

DORNELAS, J. C. A. Empreendedorismo: Transformando idéias em negócios. Rio de Janeiro: Elsevier, 2005.

DRUCKER, P. F. Inovação e Espírito Empreendedor: prática e princípios. 2. ed. São Paulo: Pioneira, 1987.

DUTRA, I. S.; PREVIDELli, J. J. Perfil do empreendedor versus mortalidade de empresas: estudo de caso do perfil do micro e pequeno empreendedor. XXVII EnANPAD. Anais. Atibaia, 2003.

FILION, L. J.. Empreendedorismo: empreendedores e proprietários-gerentes de pequenos negócios. RAE, São Paulo, v. 34, n. 2, p. 05-28, abr/jun. 1999.

- Visão e Relações: Elementos para um Metamodelo Empreendedor. RAE, São Paulo, v. 33, n. 6, p. 50-61, nov/dez. 1993.

GOSS, D. Entrepreneurship and 'the social': towards a deference-emotion theory. Human Relations, v. 58, n. 5, p. 617-636, 2005.

HAIR, J. F et al. Análise Multivariada de Dados. 5. ed. Porto Alegre: Bookman, 2005. 
HISRICH, R. D.; PETERS, M. P. Empreendedorismo. 5. ed. Porto Alegre: Bookman, 2004.

LOPEZ, Jr., G. S.; SOUZA, E. C. L. Atitude Empreendedora em Proprietários-Gerentes de Pequenas Empresas. Construção de um Instrumento de Medida. READ - ed. 48, v. 11, n. 6, nov/dez. 2005

LOPEZ, Jr., G. S.; SOUZA, E. C. L. Instrumento de medida da atitude empreendedora - IMAE: construção e validação de uma escala. In: Encontro da ANPAD, 30, Salvador/BA - Brasil. Anais ANPAD, 2006.

MALHOTRA, N., Pesquisa de marketing - Uma orientação aplicada, 4. ed. Porto Alegre: Bookman, 2004.

MATTAR, F. N. Pesquisa de Marketing: Edição compacta. São Paulo: Atlas, 2001.

McCLELLAND, D. C. The achievement society. Princeton: D. Van Nostrand Co. 1961.

A sociedade competitiva: realização e progresso social. Rio de Janeiro: Expressão e Cultura, 1972.

MELO NETO, F. P; FROES, C. Empreendedorismo social: a transição para a sociedade sustentável. Rio de Janeiro: Qualitymark, 2002.

MINTZBERG, H.; AHLSTRAND, B.; LAMPEL, J. Safári de estratégia: um roteiro pela selva do planejamento estratégico. Porto Alegre: Bookman, 2000 .

OLIVEIRA, E. M. Empreendedorismo social no Brasil: Fundamentos e Estratégias. Tese (Doutorado)Universidade Estadual Paulista - Unesp, Franca, 2004.

PEStanA, M. H.; GAGEIRO, J. N. Análise de dados para ciências sociais: a complementaridade do SPSS. Lisboa: Silabo, 2003.

SCHUMPETER, J. A. A Teoria do Desenvolvimento Econômico. Uma Investigação sobre lucros, Capital, Crédito, Juro e o Ciclo Econômico. 2 ed. São Paulo: Nova Cultural, 1985.

THOMPSON, J. L. The world of the social entrepreneur. The International Journal of Public Sector Management, vol. 15, n. 5, pp. 412-431, 2002. 